\title{
Cloud Centric Real Time Mobile Learning System for Computer Science
}

\section{Author: Shah Muhammad Butt ${ }^{1}$; Dr. Muhammad Ali Shaikh² ; Dr. Stephen John ${ }^{3}$}

\author{
Affiliation: Director IT, SMI University, Karachi ${ }^{1}$; Professor, Department of Media and \\ Communication Study, SMI University, Karachi ${ }^{2}$; Associate Professor, Department of Education, \\ SMI University, Karachi, Pakistan ${ }^{3}$ \\ E-mail:smbutt@smiu.edu.pk ${ }^{1}$;drshaikhma@gmail.com ${ }^{2}$; Stephen_blessed@yahoo.com ${ }^{3}$
}

DOI $10.26821 /$ IJSHRE.8.10.2020.8111>

\begin{abstract}
Education is an important component of life because it equips us with all that is needed to make our dreams come true. One of the most promising paradigms for education is e-learning. It is commonly referred to as the intentional use of networked information and communications technology (ICT) in teaching and learning. Some other terms are also used to describe this mode of teaching and learning including online learning, virtual learning, distributed learning, network, and web-based learning. Since the last decade, there is a growing interest in e-learning from several directions. Distance education programs see it as a logical extension of their distance education activities. The emerging concept of cloud computing and advancement in mobile devices enabled with Sensor technologies transforms many areas of modernday living. The main advantage of the cloud-centric environment is that this technology reduces the infrastructure and software cost and License for all. Mobile learning (M-learning) is considering a more effective system of providing study materials to learners anywhere anytime. It is necessary to develop the robust contents delivery mechanism for learning which can be accessed from internet-enabled mobile devices. In this paper, we discuss the impact of cloud computing and supporting technologies to acquire education in a broader dimension for the students over the country. We believe cloud-based mobile learning will surely enhance the current educational system and improve education quality at a low cost.
\end{abstract}

Keywords: Cloud Computing, Mobile Learning Cost-Effective Cloud, Mobile Cloud.

\section{INTRODUCTION}

The propagation of mobile devices that comprise smartphones, ipads, laptops, PDAs, tablets and kindles inside an ecosystem that is gradually online, creates the acceptance of program-driven through technology conceivable[1][2][3]. These gadgets are sharing the daily lives of more and more personal of all ages. Mobile learning will more obscure the peripheries of conventional learning areas. Smart economical mobile devices will build learning accessible

anytime and anywhere. Mobile devices can be used to access information and multimedia related to locations, study through mobile apps, access online class materials, and communicate through email, text, and social networks [4]. Cloud-based applications are considering Internet oriented services on shared and manageable infrastructure (Figure: 1). Due to its Elasticity and the customized software and the Infrastructure and the cost-effectiveness; the technology rapidly adopted for business, educational and other disciplines [5]. 


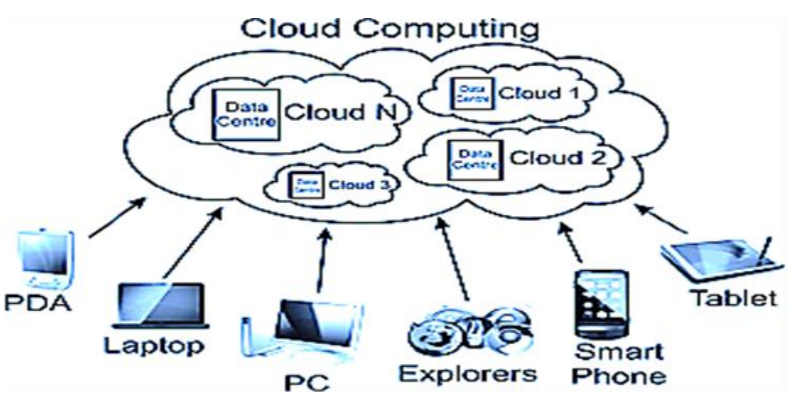

Figure-1: Cloud Computing

\section{BACKGROUND}

Providing reliable computational / storage services for learning and research has stand facing immense [6] challenges. Cloud Computing provides cost-effective and elastic IT solutions for the learning environment [7]. Cloud computing is a paradigm-shifting that provides applications, data storage and processing power over the Internet. The three service models of the cloud are SaaS, PaaS, and IaaS (Figure: 2); all enable users to run and store applications and data online. Software as a Service is the effortless method to extend software services where applications middleware is processed and accessed over the Internet. Many online word processors, spreadsheets and presentation packages are made available for public free or offered on Pay-As-You-Go (PAYGo) model; which offers data processing and storage services. These renowned public cloud providers such as Google, Microsoft and IBM offer various SaaS applications for educational purposes. Platform as a Service (PaaS) provides customized tools and development environment that enables users to design, develop, run and maintain their specific applications online; App Engine by Google, Azure by Microsoft, Amazon AWS (Amazon Web Service) and, IBM Tivoli offering PaaS Cloud Services. The Infrastructure as a Service (IaaS) model provides infrastructure services; the organizations acquire components such as computing power, Network Services and storage capacity with complete control over the entire IT infrastructure including the hosting environment and replications [8]. Clouds promote [9] the delivery of enterprise-class Network services, i.e. (virtualization, network intelligence, Storage and a robust ecosystem). The mobile platform is greatly impacted by this technology as well. Mobile Cloud Computing, speculates that the cloud will rapidly turn out to be a backbone in the mobile world, ultimately occurring the leading technique in which mobile applications operate. Users of smartphone mobiles have Internet access through $3 \mathrm{G}$ services and $\mathrm{WiFi}$ networking and the interoperability between networks [10]. The advanced functionality of smartphones allows several applications can provide context-aware information about the real-time movement, location, and reception on the mobile and store, produce, and share multimedia data using built-in cameras and microphones. According to ITU [11] at the end of 2013, over 5 billion mobile subscriptions in the world. According to Hamblen, smartphones accounted for more than 500 million in 2013.

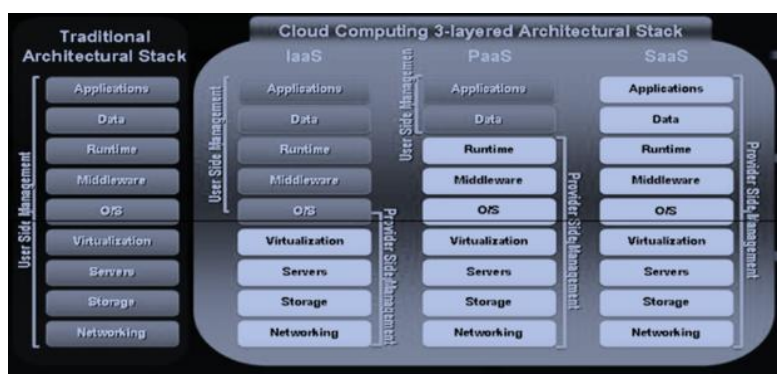

Figure 2: Traditional I.T Architecture vs. Cloud Computing Architecture.

Mobile Cloud Computing [12] supporting various applications containing M-Commerce, M-Learning, M-healthcare, M-Banking and M-Gaming and many other areas. Mobile applications obtained significant global mobile market share several mobile applications have grasped the benefit of Mobile Cloud Computing; [13] the main objective of cloud-based M-learning system for education is that the learners can obtain the data from the widely accessible pool of shared resources freely or on Pay as Use; the applications offer users with improved services in terms of storage size, better processing speed, and battery backup.

\section{PROPOSED MOBILE LEARNING SYSTEM FOR EDUCTION}

M-Learning is the enhanced approach of E-learning considering the widespread usage and development of mobile technologies; the method to deliver educational content through digital media, two recognized methodologies used for E-Learning; i.e. synchronous and asynchronous learning. Synchronous or real-time learning (Figure:3) has the advantage is that; with limited bandwidth archived and stored contents are accessed and managed without any delay[14]. 


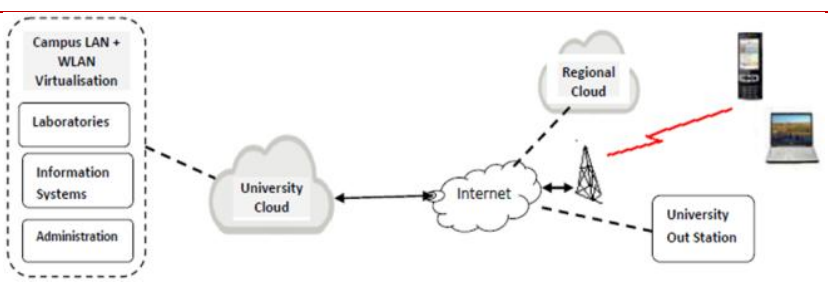

Figure-3: Mobile Cloud learning for Higher Education

To achieve synchronous communication data association and sharing of applications are required. Through this mode interacting with learning contents (text, audio and media files), student attendance, feedback and quarries, and class scheduling tools. The student's web-based registration required for the downloading of mobile applications via GPRS, $3 \mathrm{G}$ and Wi-Fi connection. The application access the Computer Science contents cloud for browsing of particular topics of the user [15]. Cloud-based contents can be documents or audio-video files, tutorials, and lectures buffered on the student's mobile device; simultaneously student assessment and results could be accessible worldwide (Figure: 4). Furthermore; context-aware documents and tutorials managed over the cloud storage [16]. The advantages of Cloud Centric Mobile education over traditional E-learning are; it is cost-effective on-demand services, [17] easily

implemented, broader network access, rapid elasticity in software services and instant updates, interoperability between hardware and software's of different venders on a single platform. Cloud automatically manages data and network load balancing, so that data and services are accessible during peak hours. Cloud-based web applications can deliver learning console for students and teachers accessing 24/7 with applications and data.

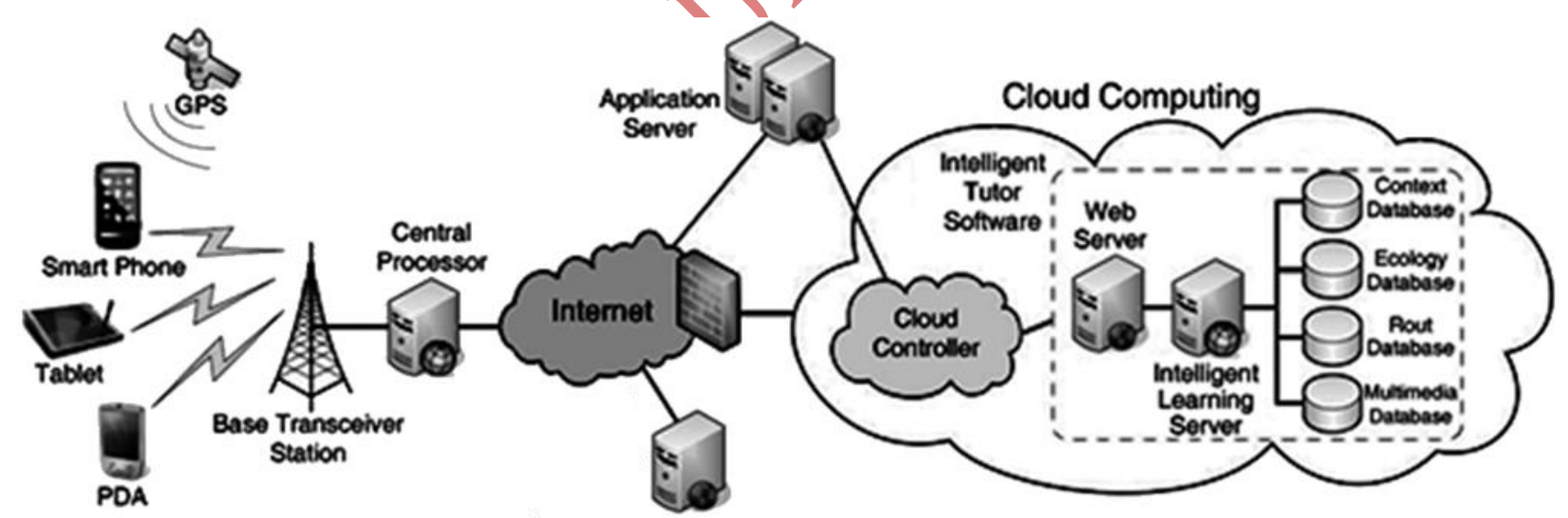

Figure 4: Cloud-Centric Mobile Learning System for Computer Science

\section{CONCLUSION \& FUTURE WORK}

The University students of the current era are more interacting with digital and mobile devices such as smartphones, laptops, and tablets. Considering the current trend, it is time and available technology, introducing the cost-effective learning system is obviously not a big challenge of the current age. Mobile learning techniques will be an essential part of the near future, facilitate students with enhanced learning components, designed for a particular discipline. The strategies may be adopted for the 
development of online course contents particularly for the students of Computer Science. Using synchronous (real-time) learning method academia and teachers could able to obtain a conventional form of computer science learning into digital and smart learning. This paper reinforces the concept of utilizing mobile learning as an interface to increase learning practices for Computer Science and in other fields of higher education. The proposed system will enhance advancements in the current educational system in order to benefit from the technology for teachers and students.

\section{REFERENCES}

[1] [1] P. Gupta and S. Gupta, "Mobile Cloud Computing: The Future of Cloud," vol. 1, no. 3, pp. 134-145, 2012.

[2] [2] H. T. Dinh, C. Lee, D. Niyato, and P. Wang, "A Survey of Mobile Cloud Computing: Architecture, Applications, and Approaches," no. Cc, pp. 1-38, 2011.

[3] [3] N. Fernando, S. W. Loke, and W. Rahayu, "Mobile cloud computing: A survey," Futur. Gener. Comput. Syst., vol. 29, no. 1, pp. 84-106, Jan. 2013.

[4] [4] N. M. Rao, "Cloud Computing Through Mobile-Learning," vol. 1, no. 6, 2010.

[5] [5] T. Toyota, H. Ba, and W. Heinzelman, "Accelerating Mobile-Cloud Computing: A Survey," 2013.

[6] [6] W. Alsaggaf, M. Hamilton, and J. Harland "Mobile Learning in Computer Science Lectures,' Int. J. e-Education, e-Business, e-Management eLearning, vol. 2, no. 6, 2012.

[7] [7] I. A. Alshalabi, S. Hamada, and K. Elleithy, "Research Learning Theories that Entail MLearning Education Related to Computer Science and Engineering Courses," vol. 2, no. Mareh, pp. 88-95, 2013.
[8] [8] D. Fesehaye, Y. Gao, K. Nahrstedt, and G. Wang, "Impact of Cloudlets on Interactive Mobile Cloud Applications," 2012 IEEE 16th Int. Enterp. Distrib. Object Comput. Conf., pp. 123-132, Sep. 2012.

[9] [9] K. Kim, S. Lee, and P. Congdon, "On CloudCentric Network Architecture for MultiDimensional Mobility Categories and Subject Descriptors," pp. 1-6, 2011.

[10] [10]E. Zaharescu, "Enhanced Virtual E-Learning Environments Using Cloud Computing Architectures," vol. 2, pp. 31-41, 2012.

[11] [11]Z. Sanaei, S. Abolfazli, A. Gani, and S. Member, "Heterogeneity in Mobile Cloud Computing : Taxonomy and Open Challenges," pp. 1-24, 2012.

[12] [12]C. Savill-smith, "Mobile learning anytime everywhere Mobile learning anytime everywhere," 2004.

[13] [13] S. Pisey, P. L. Ramteke, and B. R. Burghate, "Mobile learning exploring the challenges and opportunities of distance education," vol. 2, no. 3, pp. 19-23, 2012.

[14] [14]P. Shu, F. Liu, H. Jin, M. Chen, F. Wen, Y. $\mathrm{Qu}$, and B. Li, "eTime: Energy-efficient transmission between cloud and mobile devices," 2013 Proc. IEEE INFOCOM, pp. 195-199, Apr. 2013.

[15] [15] H. Qi and A. Gani, "Research on Mobile Cloud Computing: Review, Trend and Perspectives," 2014.

16] [16] I. A. Alshalabi and K. Elleithy, "EFFECTIVE M- LEARNING DESIGN STRATEGIES FOR COMPUTER SCIENCE AND ENGINEERING," 2012.

[17] S. Kitanov and D. Davcev, "Mobile Learning in Mobile Cloud Computing Environment," vol. 8, no. December, pp. 27-39, 2012. 